\title{
Complex Structural Dynamics at Adsorbed Alkanethiol Layers at Au(111) Single-Crystal Domains
}

\author{
F. Terán Arce, M. E. Vela, R. C. Salvarezza, and A. J. Arvia* \\ Instituto de Investigaciones Fisicoquímicas Teóricas y Aplicadas (INIFTA), \\ Sucursal 4, Casilla de Correo 16, 1900 La Plata, Argentina
}

Received May 5, 1998. In Final Form: September 2, 1998

\begin{abstract}
The structure and dynamics of dodecanethiol and butanethiol monolayers adsorbed on $\mathrm{Au}(111)$ at 298 $\mathrm{K}$ have been followed by in situ and ex situ scanning tunneling microscopy (STM). Results show that a gaslike initial adsorption stage where monatomic deep pit clustering occurs is followed by an advanced adsorption stage in which adlayer structural changes $\mathrm{p}(n \times 1) \Rightarrow(\sqrt{3} \times \sqrt{ } 3) \mathrm{R} 30^{\circ} \Leftrightarrow \mathrm{c}(4 \times 2)$ take place. The first change is interpreted as the motion of adsorbed molecules from fcc to hcp sites, and the second one is explained by the fluctuations of adsorbed molecules from hollow to bridge sites. The structural fluctuations at adsorbate domains occur simultaneously with fluctuations in the size of monatomic deep pits. These processes reveal the complexity of surface dynamics of alkanethiol adlayers on $\mathrm{Au}(111)$ at $298 \mathrm{~K}$.
\end{abstract}

\section{Introduction}

Self-assembled monolayers (SAMs) of alkanethiol molecules on single-crystal metal surfaces such as gold, ${ }^{1}$ silver, and nickel ${ }^{2}$ have been extensively studied for both scientific reasons and possible technological applications. ${ }^{3}$ Several techniques such as contact angle measurements, ${ }^{4}$ ellipsometry, ${ }^{5}$ Fourier transform infrared spectroscopy (FTIR), electrochemistry, ${ }^{5,6}$ grazing X-ray diffraction, ${ }^{7}$ He diffraction, ${ }^{8}$ second harmonic generation, ${ }^{9}$ scanning probe microscopies, ${ }^{10}$ near edge $\mathrm{X}$-ray absorption fine structure (NEXAFS) and ultraviolet photoemission spectroscopy, ${ }^{11}$ and nuclear magnetic resonance ${ }^{12}$ have been used to learn about the structure and properties of alkanethiol SAMs on single-crystal metal surfaces. In general, the procedure most commonly used for preparing thiol SAMs has been the immersion of a clean metal substrate into a diluted thiol ethanolic solution for about $24 \mathrm{~h} .{ }^{3 a}$ Alkanethiol adsorption from the vapor phase either in air or in ultrahigh vacuum (UHV) ${ }^{13}$ and immersion in pure liquid thio ${ }^{14}$ have also been used, although less frequently. The

(1) Dubois, L. H.; Nuzzo, R. G. Annu. Rev. Phys. Chem. 1992, 43, 437 (2) (a) Heinz, R. Rabe, J. P. Langmuir 1995, 11, 506 and references therein. (b) Parker, B.; Gellman, A. J. Surf. Sci. 1993, 292, 223.

(3) (a) Ulman, A. An Introduction to Ultrathin Organic Films, from Langmuir Blodgett to Self-Assembly, Academic Press: San Diego, CA 1991. (b) Swalen, J. D.; Allara, D. L.; Andrade, J. D.; Chandross, E. A.; Garoff, S.; Israelachvili, J.; McCarthy, T. J.; Murray, R.; Pease, R. F.; Rabolt, J. F.; Wynne, K. J.; Yu, H. Langmuir 1987, 3, 932.

(4) Bain, C. D.; Whitesides, G. M. J. Am. Chem. Soc. 1989, 111, 7164

(5) Porter, M. D.; Bright, T. B.; Allara, D. L.; Chidsey, C. E. D. J. Am. Chem. Soc. 1987, 109, 3559.

(6) (a) Nuzzo, R. G.; Fusco, F. A.; Allara, D. L. J. Am. Chem. Soc 1987, 109, 2358. (b) Nuzzo, R. G.; Allara, D. L. J. Am. Chem. Soc. 1983 105,4481

(7) Fenter, P.; Eisenberger, P.; Liang, K. S. Phys. Rev. Lett. 1993, 70, 2447.

(8) Chidsey, C. D. E.; Liu, G. H.; Rowntree, P.; Scoles, G. J. J. Chem. Phys. 1989, 91, 442 .

(9) Buck, M.; Grunze, M.; Eisert, F.; Fisher, J.; Träger, F. J. Vac. Sci. Technol. 1992, A10, 926.

(10) Alves, C. A.; Smith, E. L.; Porter, M. D. J. Am. Chem. Soc. 1992 114,1222

(11) Rieley, H. Price, H. J ; White, R. G.; Blyth, R. I. R.; Robinson, A. W. Surf. Sci. 1995, 331, 189

(12) Badia, A.; Demers, L.; Dickingson, L.; Morin, F. G.; Lennox, R.

B.; Reven, L. J. Am. Chem. Soc. 1997, 119, 11104

(13) Chailapakul, O.; Sun, L.; Xu, C.; Crooks, R. M. J. Am. Chem. Soc. 1993, 115, 12459

(14) Sondag-Huethorst, J. A. M.; Schönengerger, C.; Fokkink, L. G. J. J. Phys. Chem. 1994, 98, 6826. structure of alkanethiol SAMs on $\mathrm{Au}(111)$ has been described as a $(\sqrt{ } 3 \times \sqrt{ } 3) \mathrm{R} 30^{\circ}$ commensurate structure, with the alkyl chains totally extended in an all trans configuration, the axis of each molecule being tilted about $30^{\circ}$ with respect to the surface normal. ${ }^{1}$ The alkyl chains also exhibit a twist angle of about $52^{\circ}$ defined by the zigzag of the carbon atom structure in the chain. ${ }^{1}$ At $100 \mathrm{~K}$, the alkyl chain spacing is $d=0.5 \mathrm{~nm}$, but as the temperature is increased, the chain ordering gradually disappears due to thermal vibrations. ${ }^{15}$ From ab initio calculations for the alkanethiolate-gold bonding, ${ }^{16}$ it has been concluded that hollow sites, involving a second-layer Au atom located directly below the $\mathrm{S}$ atom from the thiol molecule, are the most stable sites for adsorption on $\mathrm{Au}(111)$. This type of bonding would imply a mixed $\sigma$ - and $\pi$-bonding character with a dominating contribution of the latter. The corresponding adsorption energy difference between hollow and top adsorption sites is about $25 \mathrm{~kJ} / \mathrm{mol}$, a figure which is 1 order of magnitude greater than the thermal energy at 298 K. From these calculations it has been concluded that the angle between $\mathrm{Au}(111)$ and the $\mathrm{S}-\mathrm{C}$ bond is about $180^{\circ}$ for the $\mathrm{S}$ atom sp hybridization and about $110^{\circ}$ for the $\mathrm{S}$ atom $\mathrm{sp}^{3}$ hybridization. Correspondingly, the $\mathrm{Au}(111)-\mathrm{S}$ and $\mathrm{S}-\mathrm{C}$ bond distances are 0.1826 and 0.1905 $\mathrm{nm}$ in the former case and 0.1817 and $0.1936 \mathrm{~nm}$ in the latter. The polar component of the $\mathrm{Au}(111)-\mathrm{S}$ bond involves a fraction of 0.25 of the electronic charge distributed on the $\mathrm{S}$ atom. Then, the most accepted picture for alkanethiol chemisorption on Au corresponds to that of a surface thiolate represented by $\mathrm{X}\left(\mathrm{CH}_{2}\right) \mathrm{S}^{-}-\mathrm{Au}^{+}$(ref 11) adsorbed on a 3-fold hollow site with hcp packing, where the thiolate-gold bond energy is estimated as 184 $\mathrm{kJ} / \mathrm{mol}^{17}$ However, recent experimental results have questioned this commonly accepted model by showing that alkanethiol molecules on $\mathrm{Au}(111)$ are adsorbed on a mixed bridge and hollow site configuration rather than on a single hollow site configuration. ${ }^{18}$

(15) Camilone, N.; Chidsey, C. D. E.; Liu, G. Y ; Putvinski, T. M Scoles, G. J. Chem. Phys. 1991, 94, 8493.

(16) Sellers, H.; Ulman, A.; Shnidman Y.; Eilers, J. E.; J. Am. Chem Soc. 1993, 115, 9389.

(17) Nuzzo, R. G.; Zegarski, B. R.; Dubois, L. H. J. Am. Chem. Soc. 1987, 109, 733

(18) Yenganeh, M. S.; Dougal, S. M.; Polizzotti, R. S.; Rabinowitz, P Phys. Rev. Lett. 1995, 74, 1811. 
Alkanethiol SAMs on $\mathrm{Au}(111)$ consist of domains with a $(\sqrt{ } 3 \times \sqrt{ } 3)$ R30 ${ }^{\circ}$ lattice. Other domains showing the $(4 \times 2)$ superlattice have been observed from STM images at high tunneling resistance ${ }^{19,20}$ and advanced stages of growth. The origin of this superlattice has been interpreted as due either to molecules with different twist angles of the alkyl chains ${ }^{21}$ or to the tendency to disulfide formation. ${ }^{22}$

Most of the work available in the literature on alkanethiol SAMs on well-defined surfaces has been directed toward the structural characterization of these adlayers, whereas relatively little work has been undertaken to understand the formation mechanism and dynamics of these SAMs on well-defined surfaces. Kinetic studies have focused mainly on the nucleation and growth of the SAMs themselves, and little attention has been paid to the influence the substrate surface would have on the structural changes of SAMs.

For Au(111), STM imaging has shown that the formation of alkanethiol adlayers occurs with the simultaneous appearance of pits, most of them being one Au atom deep. ${ }^{23}$ The nature of these pits is not fully understood yet. It has been argued that they result from a corrosion process at the substrate ${ }^{24}$ or from unbalanced lateral pressure of the Au surface caused by the adsorbed species. ${ }^{25}$ From STM imaging data under UHV conditions, ${ }^{26}$ it has been suggested that $\mathrm{Au}$ atoms are forced out of the surface layer by a relaxation of the compressed Au(111) herringbone structure, thereby originating pits. STM data have also shown that mass transport by surface diffusion occurs at alkanethiol adlayers on $\mathrm{Au}(111)$, and the corresponding surface diffusion rates have been measured. ${ }^{27}$ Some evidence suggesting that chemical etching is not involved in pit formation has recently been made available. $^{28}$

The self-assembly of thiol monolayers on $\mathrm{Au}(111)$ followed in ultrahigh vacuum by in situ STM ${ }^{29}$ has shown that after a gaslike stage the nucleation of striped islands takes place. The striped phase has been assigned to the presence of thiol molecules parallel to the substrate and acts as a precursor for the formation of a dense solid phase with the molecular axes placed normal to the substrate. The presence of a diluted striped $\mathrm{p}(n \times 1)$ phase previous to the formation of the stable thiol adlayer has also been reported. ${ }^{30}$

This paper deals with time-dependent aspects of 1-dodecanethiol adsorption on $\mathrm{Au}(111)$ from the pure liquid at $298 \mathrm{~K}$ followed by in situ STM imaging. Results are

(19) Yamada, R.; Uosaki, K. Langmuir 1997, 13, 5218.

(20) Delamarche, E.; Michel, B.; Gerber, Ch.; Anselmetti, D.; Guntherodt, H. J.; Wolf, H.; Ringsdorf, H. Langmuir 1994, 10, 2869.

(21) Anselmetti, D.; Baratoff, A.; Güntherodt, H. J.; Delamarche, E.; Michel, B.; Gerber, Ch.; Kang, H.; Wolf, H.; Ringsdorf, H. Europhys. Lett. 1994, 27, 365.

(22) Fenter, P.; Eberhardt, A.; Eisenberger, P. Science 1994, 266 , 1216. Voets, J.; Gerritsen, J. W.; Grimbergen, R. F. P.; Van Kempe, H. Surf. Sci. 1998, 399, 316.

(23) Schönengerger, C.; Sondag-Huethorst, J. A. M.; Jorritsma, J.; Fokkink, L. G. J. Langmuir 1994, 10, 611.

(24) (a) Edinger, K.; Golzhäuser, A.; Demota, K.; Wöll, Ch.; Grunze, M. Langmuir 1993, 9, 4. (b) Edinger, K.; Grunze, M.; Wöll, Ch. Ber. Bunsen-Ges. Phys. Chem. 1997, 101, 1811.

(25) McDermott, C. A.; McDermott, M. T.; Green, J. B.; Porter, M. D. J. Phys. Chem. 1995, 99, 13257.

(26) Poirier, G. E. Langmuir 1997, 13, 2019.

(27) (a) Terán Arce, F.; Vela, M. E.; Salvarezza, R. C.; Arvia A. J. Electrochim. Acta, in press. (b) Stranick, S. J.; Parikh, A. N.; Allara, D. L.; Weiss, P. S. J. Phys. Chem. 1994, 98, 11136. (c) McCarley, R. L.; Dunaway, O. J.; Willicut, R. J. Langmuir 1993, 9, 2775.

(28) Dishner, M. H.; Hemminger, J. C.; Feher, F. J. Langmuir 1997, 13, 2318.

(29) Poirier, G. E.; Pylant, E. D. Science 1996, 272, 1145

(30) Poirier, G. E.; Tarlov, M. J. Langmuir 1994, 10, 2853. compared to those obtained by ex situ STM imaging from the adsorption of 1-butanethiol on the same substrate. For 1-dodecanethiol adsorption on $\mathrm{Au}(111)$ from the liquid, the gaslike stage observed in UHV is followed by the formation of the striped $p(6 \times 1)$ phase. However, in contrast to previous results, high-resolution images show the $(\sqrt{ } 3 \times \sqrt{ } 3)$ R30 $0^{\circ}$ lattice inside the striped phase. Similar results are obtained for the $\mathrm{p}(4 \times 1)$ formed in 1 -butanethiol. In addition, for both systems unexpected structural fluctuations $(\sqrt{ } 3 \times \sqrt{ } 3) \mathrm{R} 30^{\circ} \Leftrightarrow \mathrm{c}(4 \times 2)$ are observed. Results from this study allow us to propose a model describing the origin of the $c(4 \times 2)$ structure and to explain the kinetics of pit displacement and coalescence at 1-dodecanethiolcovered Au(111) terraces by a surface mass transport mechanism, in which either an interface transfer along pit borders or a non-steady-state surface diffusion of adsorbed molecules becomes the rate-determining step.

\section{Experimental Section}

Nanoscope III STM equipment (Digital Instruments, Santa Barbara, CA) was employed. STM experiments were performed utilizing commercial $\mathrm{Pt}$-Ir tips (Digital Instruments, Santa Barbara, CA) and, occasionally, PtIr tips snipped with wire cutters. When necessary, to correct for tilt and bow, images were plane removed and flattened using the image-processing software of the instrument. This software was also employed to determine the pit size resulting from STM images.

Gold films evaporated on glass (250-nm thick gold layer onto "Robax" glass, AF Berliner glass KG, Germany) with a 2-nm thick chromium undercoating for better adhesion to the glass surface were used as substrates. To obtain large $\mathrm{Au}(111)$ terraces, these substrates were flame annealed. ${ }^{31}$ Before each experiment those substrates that had not been used immediately after their preparation were immersed for about $3 \mathrm{~min}$ in a $70 \% \mathrm{H}_{2} \mathrm{SO}_{4}+30 \%$ $\mathrm{H}_{2} \mathrm{O}_{2}$ solution for additional cleaning. Occasionally, this procedure led to pit formation, as has been observed for $\mathrm{Au}(111)$ after immersion in either thiol-containing solutions, ${ }^{32}$ or sulfochromic acid, ${ }^{33}$ as well as from oxidationreduction cycles in acid solutions. ${ }^{34}$ AFM and STM at $298 \mathrm{~K}$ characterized substrates used in this work in air.

Butanethiol films were formed by dipping for $24 \mathrm{~h}$ the Au substrate in a $50 \mu \mathrm{M}$ ethanolic solution of 1-butanethiol, prepared from 1-butanethiol (Fluka) and 99.99\% ethanol (Merck). Then, the thiol-covered substrate was rinsed with ethanol, and immediately afterward a chosen domain was ex situ sequentially STM imaged. STM imaging was performed at $298 \mathrm{~K}$ under ex situ conditions for butanethiol and in situ conditions for dodecanethiol. In situ STM experiments were performed in a liquid cell. After a region for imaging had been located, about $50 \mu \mathrm{L}$ of pure 1-dodecanethiol (Fluka) was put on the Au substrate while the tip was scanning the surface under an applied bias potential. Since 1-dodecanethiol is nonconductive, the possibility of any electrochemical reactions under these conditions should be discarded. The absence of Faradaic currents was confirmed by using low tunneling currents. Values in the ranges $1.5 \mathrm{~V} \leq E_{\mathrm{b}} \leq 2.5 \mathrm{~V}$ and $100 \mathrm{pA} \leq i_{\mathrm{T}}$ $\leq 150 \mathrm{pA}$ for the bias voltage $\left(E_{\mathrm{b}}\right)$ and tunneling current, respectively, for 1-dodecanethiol in situ measurements and $E_{\mathrm{b}}=0.9 \mathrm{~V}$ and $i_{\mathrm{T}}=200 \mathrm{pA}$ for butanethiol ex situ measurements were used. For these ranges of operating

(31) Kolb, D. M.; Dakkouri, A. S.; Batina, N. In Nanoscale Probes of the Solid/Liquid Interface; Gewirth, A. A.; Siegenthaler, H., Eds.; NATO ASI Series E288; Kluwer: Dordrecht, 1995.

(32) Kim, Y. K.; Bard, A. J. Langmuir 1992, 8, 1096.

(33) Truong, K. D.; Rowntree, P. A. J. Phys. Chem. 1996, 100, 19917.

(34) Honbo, H.; Sugawara, S.; Itaya, K. Anal. Chem. 1990, 62, 272. 
a
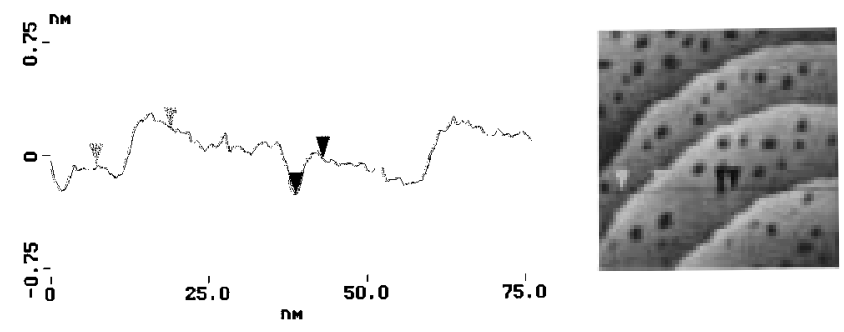

75.0

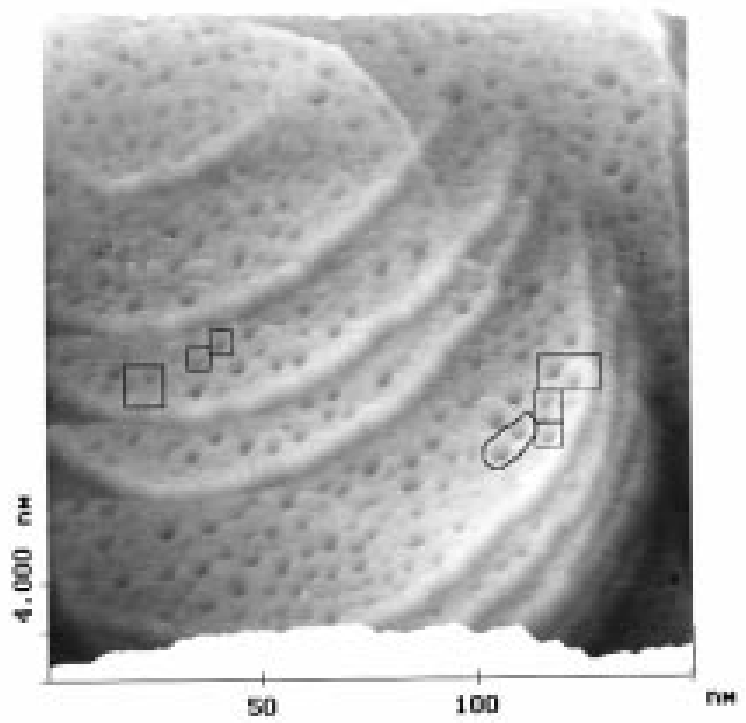

b
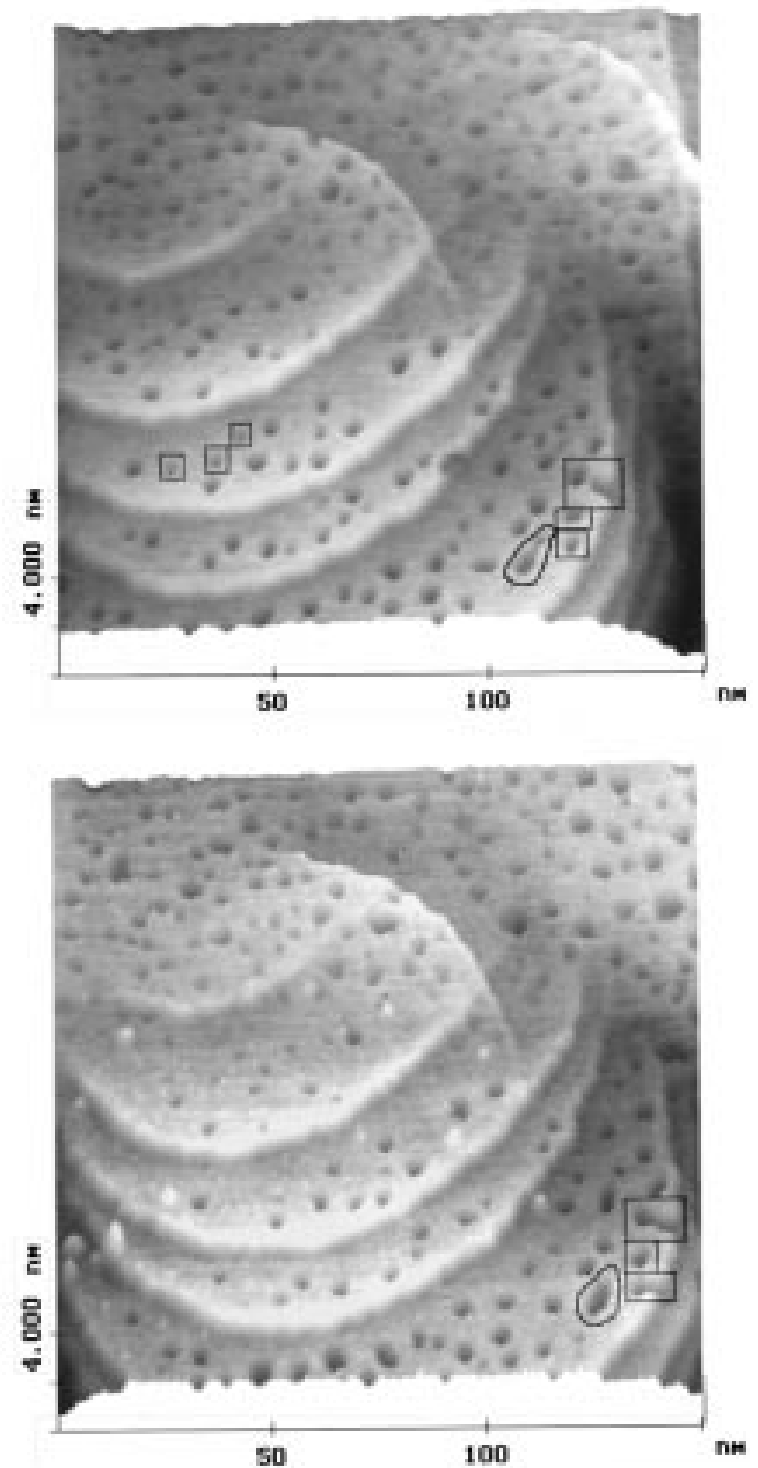

Figure 1. In situ STM images of 1-dodecanethiol-covered $\mathrm{Au}(111)$ at $298 \mathrm{~K}$. (a) Cross section showing terraces separated by monatomic high steps and monatomic deep pits. (b-d) STM images of the same domain taken for different Au(111)/pure 1-dodecanethiol contacting times $t$ : (b) $t=9 \min 6 \mathrm{~s}$; (c) $t=21 \min 54 \mathrm{~s}$; (d) $t=30 \min 12 \mathrm{~s}$.

variables, no dependence of the STM images on $E_{\mathrm{b}}$ could be observed.

\section{Results and Interpretation}

3.1. Initial Stages of Alkanethiol Adsorption. Adsorbate Surface Mobility. Sequential in situ STM images (Figure 1) of 1-dodecanethiol adlayers on $\mathrm{Au}(111)$ obtained at substrate/1-dodecanethiol solution contacting times in the range $0<t<30 \mathrm{~min}$, that is, at the initial adsorption stages, show smooth terraces and pits $0.24 \mathrm{~nm}$ in depth, that is, monatomic deep pits on $\mathrm{Au}(111)$ (Figure 1a). Attempts to obtain molecular resolution on these terraces failed, as adsorbed alkanethiol molecules at this stage appear to be too mobile to be imaged by STM. The alkanethiol adlayer involves a rich dynamics of surface defects, that is, changes in the size of monatomic deep pits and diffusion of single pits on terraces, leading to either pit coalescence or pit-step edge coupling. Thus, from Figure 1b (pits enclosed by rectangles on the right side of the image) distances along the $x$-direction separating pits and the neighboring step edge are between 6.4 and $8.2 \mathrm{~nm}$. Later, one of those pits disappears, being incorporated into the step edge (Figure 1c), and the same occurs with other pits a little bit later (Figure 1d). Furthermore, pit separation (Figure 1b, pits inside the area indicated by the closed curve) is approximately 5.6 $\mathrm{nm}$, and it gradually decreases as both pits merge together, forming a single larger pit of $9.1 \mathrm{~nm}$ average radius (Figure 1d). It should be noted that those pits enclosed by rectangles (Figure 1b, left side of the image) decrease progressively in size and finally disappear.

As the substrate/alkanethiol solution contacting time is increased, the above-described global process results in an increase in the average size of larger pits, and smaller pits tend to disappear, leading to a decrease in pit density $(n)$ with time $(t)$ (Figure 2a). From the time dependence of $\langle R\rangle$, the average pit radius, it is possible to establish the likely mechanism controlling pit relaxation. In fact, equations emerging from the clustering theory ${ }^{35}$ provide the time dependence of $R_{\mathrm{c}}(t)$, the critical radius of the pit,

$$
\left\langle R_{\mathrm{c}}(t)\right\rangle=R(0)\left[1+t / \tau_{\mathrm{c}}\right]^{1 /(m+2)}
$$

$\tau_{\mathrm{c}}$ being the time constant for clustering and $m$ the

(35) Zinke-Allmang, M.; Feldman, L.; Grabow, M. H. Surf. Sci. Rep. 1992, 16, 377 . 

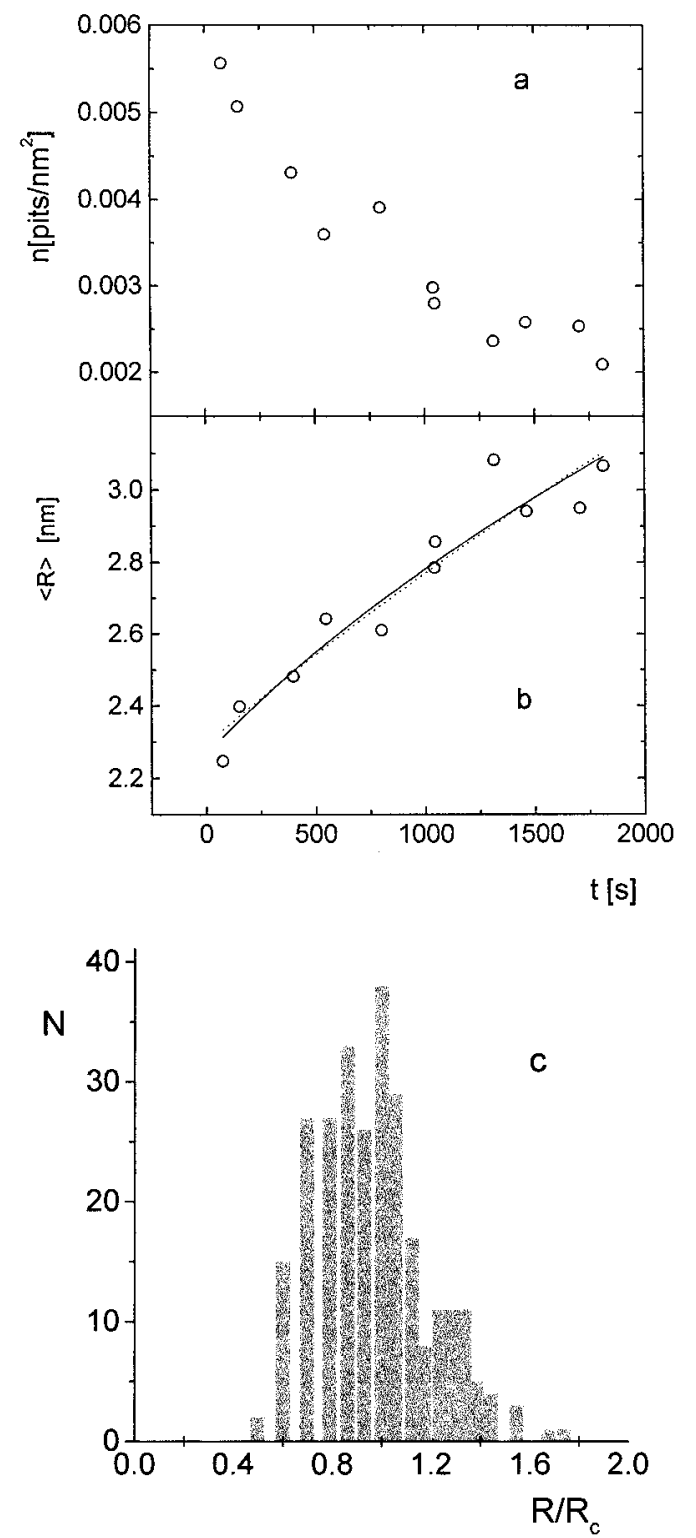

Figure 2. $n$ vs $t$ plot; (b) $\langle R\rangle$ vs $t$ plot; (c) $N$ vs $R / R_{\mathrm{c}}$ plot.

dimensionless exponent in ripening which provides an indication of the rate-determining step of the clustering process. When $m=0(x=1 / 2)$, the rate process can be related either to a non-steady-state surface diffusion or to an interface transfer, whereas when $m=1(x=1 / 3)$, coalescence is governed by steady-state surface diffusion. Following a conventional curve-fitting procedure for the $\langle R\rangle$ versus $t$ data (Figure $2 \mathrm{~b}$ ), it is difficult to ascertain a reliable value of $m$. This situation, however, can be to some extent circumvented considering the pit size distribution function.

According to the clustering theory, ${ }^{35}$ the shape of the cluster size distribution function depends on the value of $m$. Thus, for $m=0$, the maximum of the distribution function yields $\left(R / R_{\mathrm{c}}\right)_{\mathrm{M}}=1$, the full width at half-maximum is $W_{1 / 2}=0.9$, and the upper limiting value of the distribution function results in $\left(R / R_{\mathrm{c}}\right)_{\lim } \leq 2$; and for $m=$ $1,\left(R / R_{\mathrm{c}}\right)_{\mathrm{M}}=1.13, W_{1 / 2}=0.5$, and $\left(R / R_{\mathrm{c}}\right)_{\lim } \leq 1.5$. Our experimental data show that the pit size distribution for the pit clustering plotted as $N$, the number of pits, versus the $R / R_{\mathrm{c}}$ ratio (Figure $2 \mathrm{c}$ ) yields $\left(R / R_{\mathrm{c}}\right)_{\mathrm{M}}=1, W_{1 / 2} \cong 0.6$, and $\left(R / R_{\mathrm{c}}\right)_{\text {lim }} \approx 1.65$. These figures agree with the theoretical predictions for $m=0$. It should be noted that $m=0$ has been observed for the time dependence of $\langle R\rangle$

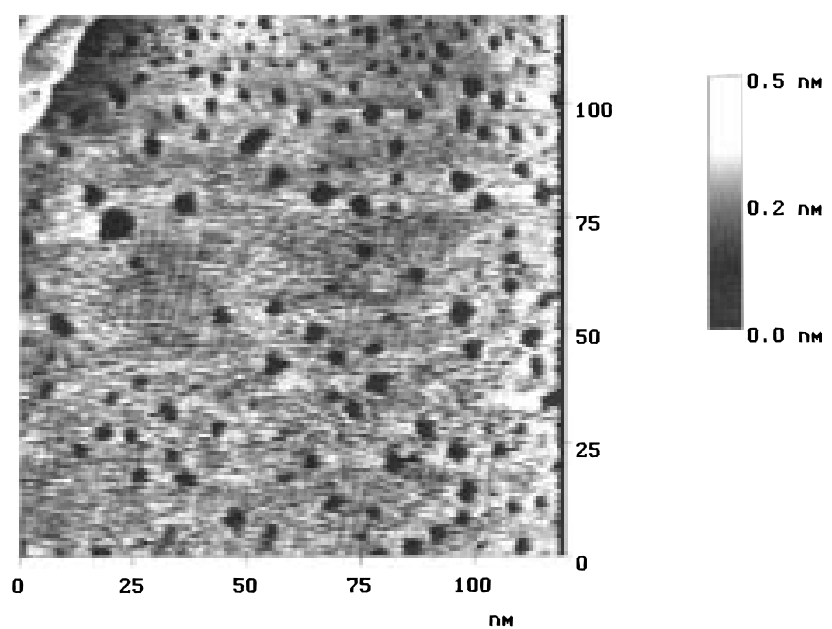

Figure 3. In situ STM images of 1-dodecanethiol-covered $\mathrm{Au}(111)$ at $298 \mathrm{~K}$ for $t=3 \mathrm{~h}$.

on alkanethiol-covered $\mathrm{Au}^{36}$ at different temperatures and interpreted in terms of a rate-determining step involving the adsorption-desorption of monovacancies at pit edges. However, our results from in-situ STM imaging in pure liquid 1-dodecanethiol cannot be directly compared to those results for dilute solutions, as in this case the uptake of thiol by the surface is slower.

From STM data it can then be concluded that changes in both pit size and pit density occur at the early stages of 1-dodecanethiol adsorption on $\mathrm{Au}(111)$ where a gaslike adlayer structure is present. The appearance of striped ordered adlayer domains from disordered ones (Figure 3) can be taken as an indication that the initial adsorption stage has been completed.

3.2. Advanced Stages of Alkanethiol Adsorption on $\mathrm{Au}(111)$ at $298 \mathrm{~K}$. 3.2.1. Structural Changes at the 1-Dodecanethiol Adlayer Observed by in situ STM Imaging. The formation of the 1-dodecanethiol stripe like adlayer pattern (Figure 4a) occurs after keeping the $\mathrm{Au}(111)$ substrate in contact with pure 1-dodecanethiol for 15-60 min. High-resolution images of this pattern after $3 \mathrm{~h}$ (Figure $4 \mathrm{~b})$ reveal the hexagonal $(\sqrt{ } 3 \times \sqrt{ } 3) \mathrm{R} 30^{\circ}$ lattice with the nearest neighbor distance $d=0.5 \mathrm{~nm}$, and a stripe-to-stripe separation that is six times the nearest neighbor distance in the hexagonal lattice, resulting in SAM domains with a $\mathrm{p}(6 \times 1)$ superlattice structure. This lattice, however, is no longer observed about $4 \mathrm{~min}$ later (Figure 4c), as it is replaced by a new structure with the periodicity of the $(\sqrt{ } 3 \times \sqrt{ } 3) \mathrm{R} 30^{\circ}$ lattice (Figure $\left.4 \mathrm{~d}\right)$. During the $\mathrm{p}(6 \times 1) \Longrightarrow(\sqrt{ } 3 \times \sqrt{ } 3) \mathrm{R} 30^{\circ}$ lattice change small depressions that can be attributed to the formation of new pits are observed.

Sequential in situ STM images (Figure 5a and b) of a 1-dodecanethiol SAM on Au(111) kept for about $3 \mathrm{~h}$ in contact with liquid alkanethiol show several domains having the $(\sqrt{ } 3 \times \sqrt{ } 3)$ R30 lattice. After a few seconds from the capture of the image seen in Figure 5a, structural fluctuations from the $(\sqrt{3} \times \sqrt{ } 3)$ R30 $0^{\circ}$ lattice to two $c(4 \times 2)$ superlattice structures characterized by a 1-nm inter-row separation can be observed (Figure 5b). In this image rows at the upper central part of the image correspond to the zigzag $c(4 \times 2)$ structure with the intermolecular distance $d=0.5 \mathrm{~nm}$, whereas rows at the lower part of the image involve the rectangular $\mathrm{c}(4 \times 2)$ structure with $d=0.86 \mathrm{~nm}$. A magnified image of this region (Figure

(36) (a) Cavalleri, O.; Hirstein, A.; Kern, K. Surf. Sci. 1995, 340 L960. (b) Bucher, J. P.; Santesson, L.; Kern, K. Langmuir 1994, 10, 979. 

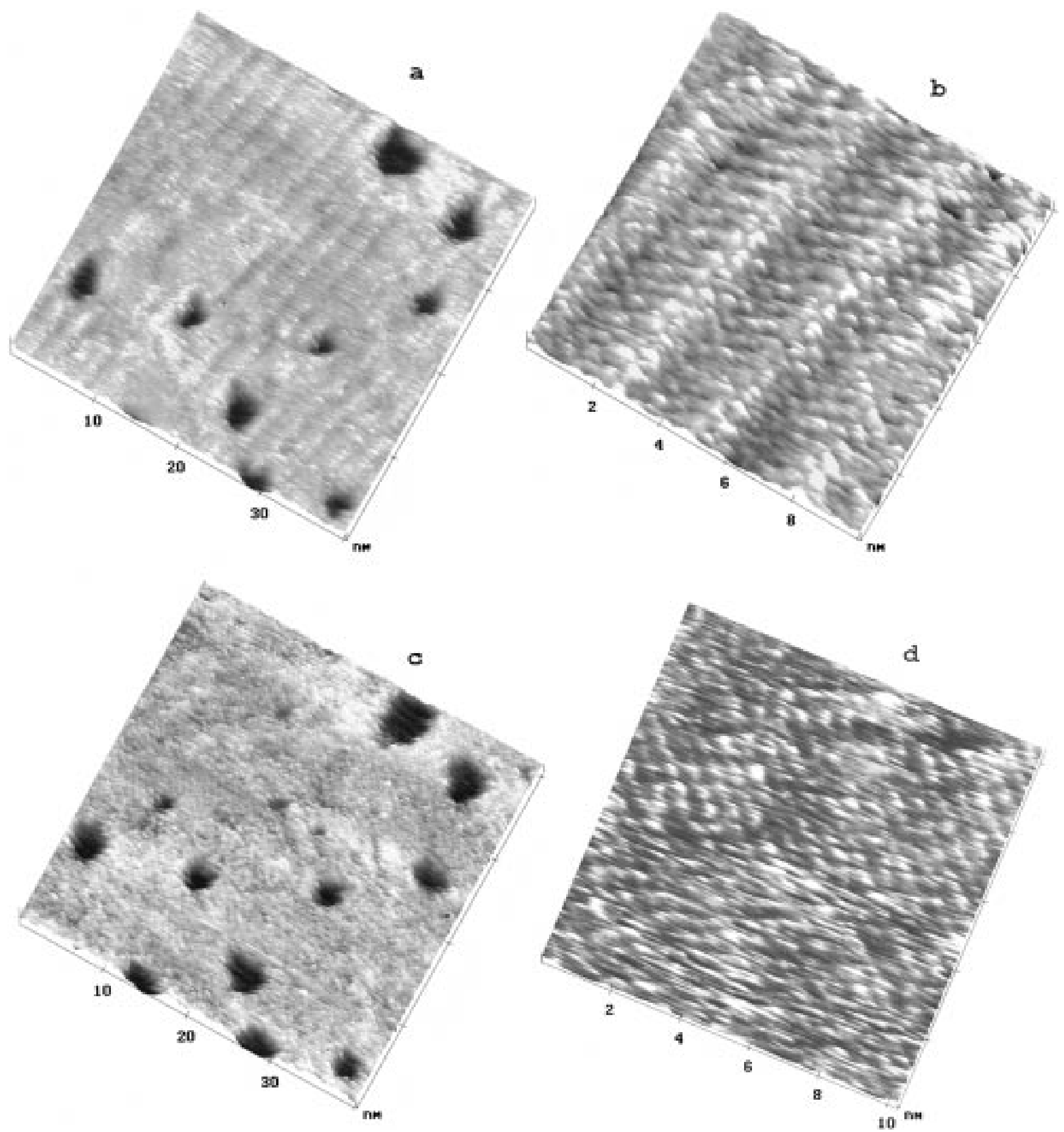

Figure 4. In situ STM images of 1-dodecanethiol-covered $\mathrm{Au}(111)$ at $298 \mathrm{~K}$ showing the spontaneous change occurring at ordered adlayer domains. (a) Stripelike pattern resulting from $t=3 \mathrm{~h}$. (b) High-resolution image of the image shown in part a. The $\mathrm{p}(6 \times 1)$ lattice can be observed. (c) Image of the same domain shown in part a for $t=3 \mathrm{~h} 4 \mathrm{~min}$. (d) High-resolution image of the image shown in part c. The $(\sqrt{ } 3 \times \sqrt{ } 3)$ R3 $30^{\circ}$ lattice can be observed.

5c) shows different domains (indicated by arrows) with the rectangular $\mathrm{c}(4 \times 2)$ superlattice. A STM image of the same region taken 3 min later (Figure $5 \mathrm{~d}$ ) shows only the zigzag c $(4 \times 2)$ superlattice (upper part of the image), the rectangular $\mathrm{c}(4 \times 2)$ superlattice being replaced by the $(\sqrt{ } 3 \times \sqrt{3})$ R30 $0^{\circ}$ lattice. Unfortunately, the quality of the images deteriorates progressively so that the possibility of detecting new structural fluctuations taking place in this region is prevented. However, the sequence of images shown in Figure 5 provides a sound support to the $(\sqrt{ } 3 \times \sqrt{ } 3) \mathrm{R} 30^{\circ} \Leftrightarrow \mathrm{c}(4 \times 2)$ structural fluctuations that have recently been observed. ${ }^{37}$ It should be noted that in a number of images the $c(4 \times 2)$ superlattice remained stable under scanning, as has been already reported. ${ }^{38}$ A detailed analysis of these images also reveals that changes in the SAM lattice are accompanied by changes in the size and shape of neighbor pits.

3.2.2. Structural Changes at 1-Butanethiol SAMs Observed by ex Situ STM. A $50 \times 50 \mathrm{~nm}^{2}$ ex situ STM image (Figure 6a) of a 1-butanethiol SAM on Au(111) shows three thiol-covered $\mathrm{Au}(111)$ terraces separated by monatomic steps 0.24-nm deep. The upper terrace shows

(37) Terán Arce, F.; Vela, M. E.; Salvarezza, R. C.; Arvia, A. J. J. Chem. Phys., in press.

(38) Touzov, I.; Gorman, C. B. J. Phys. Chem. B 1997, 101, 5263. 

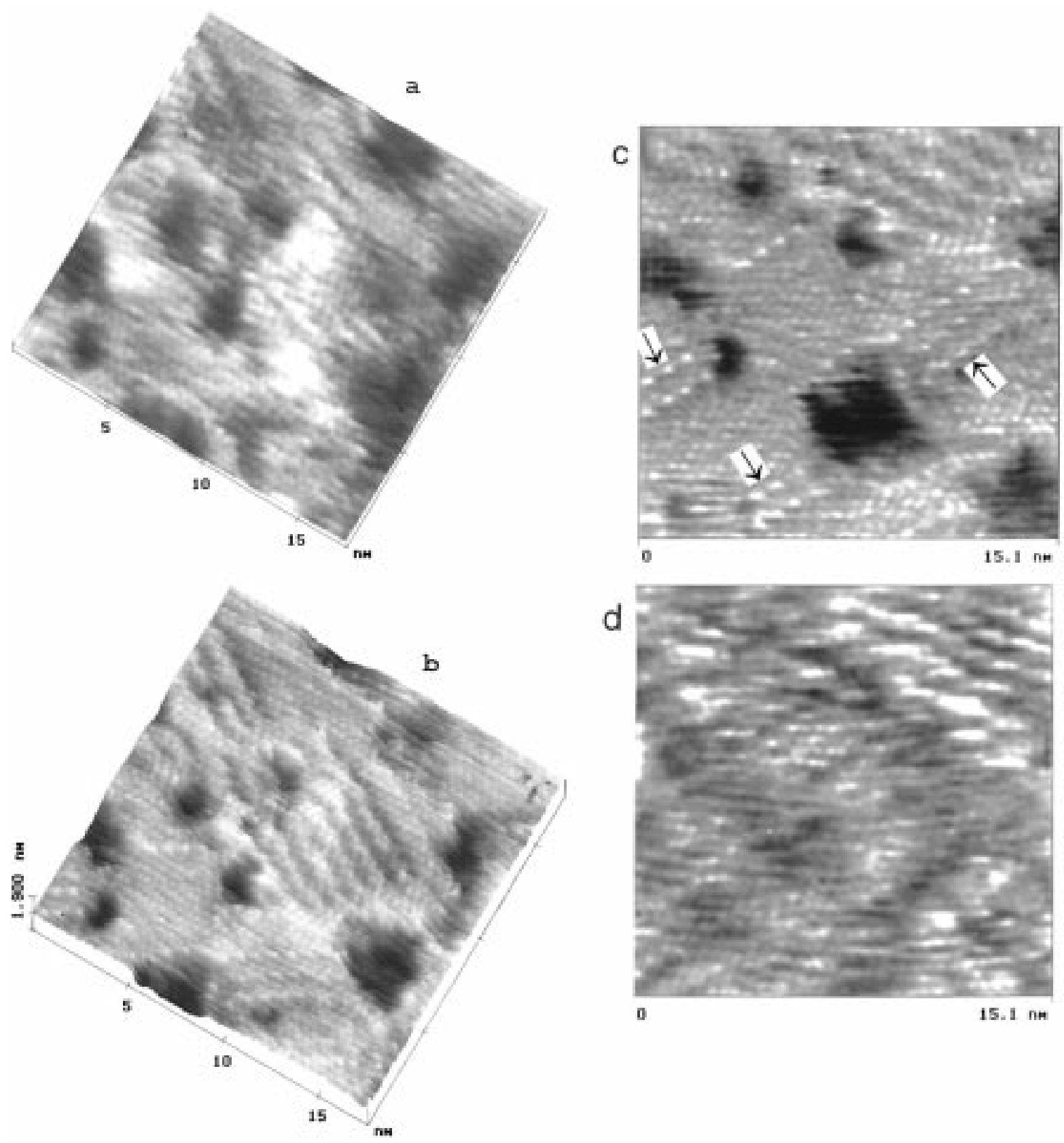

Figure 5. In situ STM images of 1-dodecanethiol-covered $A u(111)$ at $298 \mathrm{~K}$ showing the change from the $(\sqrt{ } 3 \times \sqrt{ } 3) \mathrm{R} 30^{\circ}$ lattice (a) to the $\mathrm{c}(4 \times 2)$ lattice (b). The difference in imaging time between parts a and b is $25 \mathrm{~s}$. (c) Top view STM image of a region close to that imaged in part $b$. Arrows indicate domains of the rectangular $c(4 \times 2)$ supperlattice. (d) Top view STM image of the same region imaged in part c. Note the disappearance of the rectangular $\mathrm{c}(4 \times 2)$ supperlattice domains. The difference in imaging time between parts $\mathrm{c}$ and $\mathrm{d}$ is $180 \mathrm{~s}$.

a single molecular domain consisting of a striped adsorbate lattice; the lower terrace consists of a disordered adlayer, and the wide central terrace shows the coexistence of the striped adsorbed lattice and other structures. A highresolution ex situ STM image of the same SAM domain (Figure 6b) shows that the wide stripelike adlayer domain corresponds to a $\mathrm{p}(4 \times 1)$ superstructure of the $(\sqrt{ } 3 \times \sqrt{ } 3)$ $\mathrm{R} 30^{\circ}$ lattice. The corrugation between bright and dark stripes in this domain is approximately $0.025 \mathrm{~nm}$. The central domain of this terrace, occupying about $20 \times 20$ $\mathrm{nm}^{2}$ (Figure $\left.6 \mathrm{a}\right)$, corresponds to the zigzag $\mathrm{c}(4 \times 2)$ superlattice, as can be observed in the zoomed image (Figure $6 c$ ). The corrugation of this domain is about $0.015 \mathrm{~nm}$, a figure somewhat smaller than that resulting from the $\mathrm{p}(4 \times 1)$ superstructure. Finally, at the central region of Figure $6 a$ there is a small domain between the $c(4 \times 2)$ and $\mathrm{p}(4 \times 1)$ superstructures, in which the $(\sqrt{ } 3 \times \sqrt{ } 3) \mathrm{R} 30^{\circ}$ lattice is distinghishable (Figure 6c, lower left corner).

The separation between bright and gray neighbor spots resulting from the cross section of the $\mathrm{c}(4 \times 2)$ lattice (Figure $7 \mathrm{a})$ is $0.45 \mathrm{~nm}$, a figure smaller than the separation of $0.50 \mathrm{~nm}$ expected from the $(\sqrt{ } 3 \times \sqrt{ } 3) \mathrm{R} 30^{\circ}$ lattice (Figure $7 \mathrm{~b})$. From similar images that have been obtained for octanethiol on $\mathrm{Au}(111),{ }^{30}$ we measured the same difference in spot separation as that found in our work. The difference $0.05 \mathrm{~nm}$ is consistent with a displacement of adsorbed alkanethiol molecules from hollow to bridge sites of the substrate. The difference in spot contrast could be explained by a difference in the local charge density resulting from the adsorption of S heads at different sites.

Taking into account that STM images the S head of thiol molecules, ${ }^{39}$ our results indicate that $S$ heads in the 

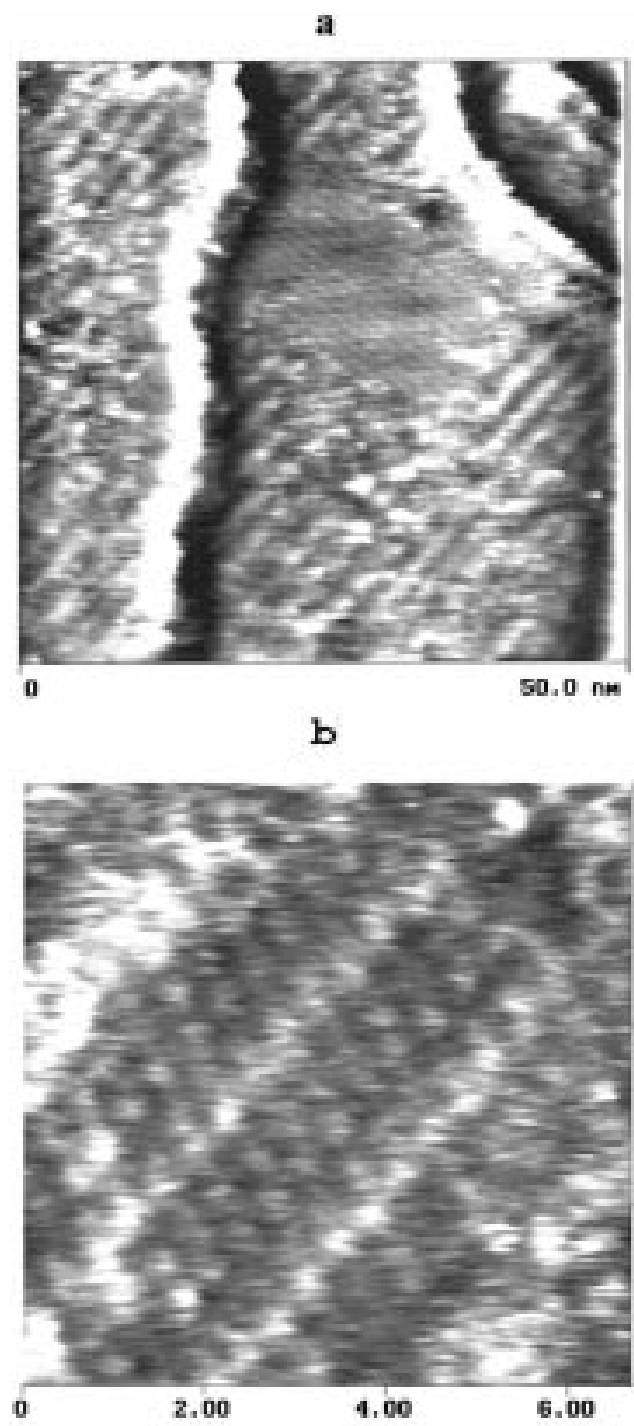

c

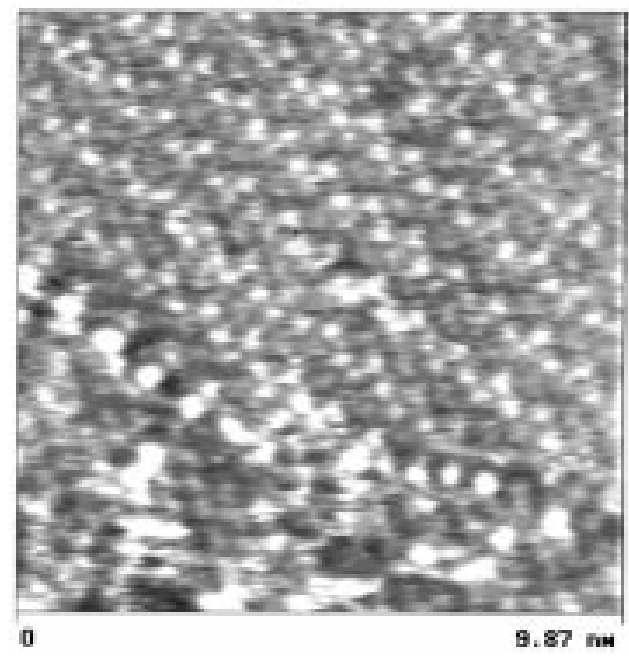

Figure 6. (a) Ex situ STM image of 1-butanethiol-covered $\mathrm{Au}(111)$ at $298 \mathrm{~K}$ for $t=24 \mathrm{~h}$ showing three terraces separated by monatomic-high steps. Each terrace consists of distinguishable adlayer domains and a few pits. (b) High-resolution image of the stripelike pattern appearing at the right-hand corner of the central terrace in part a. The $\mathrm{p}(4 \times 1)$ lattice can be observed. (c) High-resolution image taken at the center of the central terrace shown in part a, showing the $\mathrm{c}(4 \times 2)$ lattice and a small domain at the lower left corner in which the $(\sqrt{ } 3 \times \sqrt{ } 3) \mathrm{R} 30^{\circ}$ lattice can be observed. $c(4 \times 2)$ superlattice are located at different sites on the $\mathrm{Au}(111)$ surface, as shown in Figure 7c. This new structural model for the $\mathrm{c}(4 \times 2)$ lattice is supported by recent sum-frequency generation spectral data. ${ }^{18}$

Domains of 1-butanethiol SAMs on Au(111) with different lattice structures including their boundary regions can be seen in the sequential high-resolution STM imaging of a $10 \times 10 \mathrm{~nm}^{2}$ surface (Figure 8). Narrow lines in the upper half of Figure 8 a correspond to the $c(4 \times 2)$ superstructure, and broad stripes in the lower half of the same image correspond to the $\mathrm{p}(4 \times 1)$ superlattice. No structural change in $\mathrm{c}(4 \times 2)$ and $\mathrm{p}(4 \times 1)$ superlattice domains could be observed after scanning the same region for about $200 \mathrm{~s}$. To discard any tip-induced effect on the SAM structures, the tip was subsequently moved to the lower domain of the image shown in Figure 8a, and scanning was continued there for $120 \mathrm{~s}$, resulting again in no change at the $\mathrm{p}(4 \times 1)$ superstructure. Immediately afterward the tip was moved back to the $\mathrm{c}(4 \times 2)$ domain of the image depicted in Figure 8a. A new STM image of this region taken after $420 \mathrm{~s}$ from the initiation of the sequential imaging (Figure $8 \mathrm{~b})$ shows that the $\mathrm{c}(4 \times 2)$ superstructure has disappeared from the upper domain, being replaced by the $(\sqrt{3} \times \sqrt{ } 3) \mathrm{R} 30^{\circ}$ lattice. However, the $\mathrm{c}(4 \times 2)$ superlattice could be recovered after scanning the same domain for $41 \mathrm{~s}$ (Figure 8c). Shortly afterward, however, the $(\sqrt{ } 3 \times \sqrt{ } 3)$ R3 $30^{\circ}$ lattice can be clearly seen once again (Figure 8d), this structure remaining stable under further scanning for several min. Therefore, these results confirm that reversible $\mathrm{c}(4 \times 2) \Leftrightarrow(\sqrt{ } 3 \times \sqrt{ } 3) \mathrm{R} 30^{\circ}$ structural fluctuations occur spontaneously at alkanethiol SAMs on $\mathrm{Au}(111)$.

\section{Discussion}

Results from this work indicate that the formation of 1-dodecanethiol and 1-butanethiol SAMs on Au(111) at $298 \mathrm{~K}$ comprises an initial stage lasting about 15-60 min that involves the appearance of a disordered gaslike adlayer accompanied by pit clustering, and an advanced stage in which ordered adsorbate domains are formed. At the initial stage, the rate-determining step of pit clustering can be described as the adsorption-desorption of monovacancies at pit edges, as has been reported for alkanethiolcovered Au. ${ }^{36}$ The advanced stage involves a complex dynamics of adsorbate structures coupled with fluctuations in pit size.

At the beginning of the advanced stage, the structures most frequently observed for alkanethiol adlayers on $\mathrm{Au}(111)$ are of the type $\mathrm{p}(n \times 1)$, specifically $\mathrm{p}(4 \times 1)$ for 1-butanethiol and $\mathrm{p}(6 \times 1)$ for 1 -dodecanethiol. These superlattices appear to be equivalent to the stripelike structures that have already been reported at the initiation stage of adsorption ${ }^{29,30}$ and interpreted as alkanethiol molecules either lying parallel to the substrate or as a diluted alkanethiol adlayer. In contrast to this interpretation, our results show that the $(\sqrt{ } 3 \times \sqrt{ } 3)$ R30 $0^{\circ}$ lattice is present at stripe domains at the advanced adsorption stage.

STM images of the 1-dodecanethiol SAM show that the $\mathrm{p}(6 \times 1)$ lattice undergoes an irreversible change to the $(\sqrt{ } 3 \times \sqrt{ } 3) \mathrm{R}^{\circ} 0^{\circ}$ lattice. Considering that the $\mathrm{p}(n \times 1)$ structure consists of alkanethiol molecules alternatively located at fcc (bright spot) and hcp (low contrast spot) hollow sites of $\mathrm{Au}(111)$, the irreversible $\mathrm{p}(6 \times 1) \Longrightarrow(\sqrt{ } 3 \times \sqrt{ } 3) \mathrm{R} 30^{\circ}$ structural change would imply the displacement of the

(39) (a) Schönengerger, C.; Jorritsma, J.; Sondag-Huethorst, J. A. M.; Fokkink, L. G. J. J. Phys. Chem. 1995, 99, 3259. (b) Karpfen, A. J. Chem. Phys. 1981, 75, 238. 


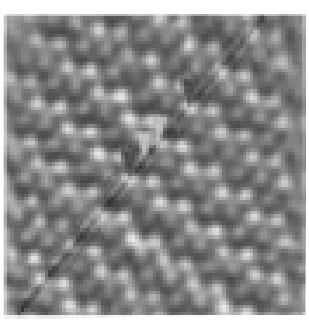

a

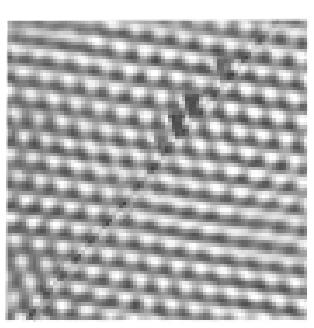

b
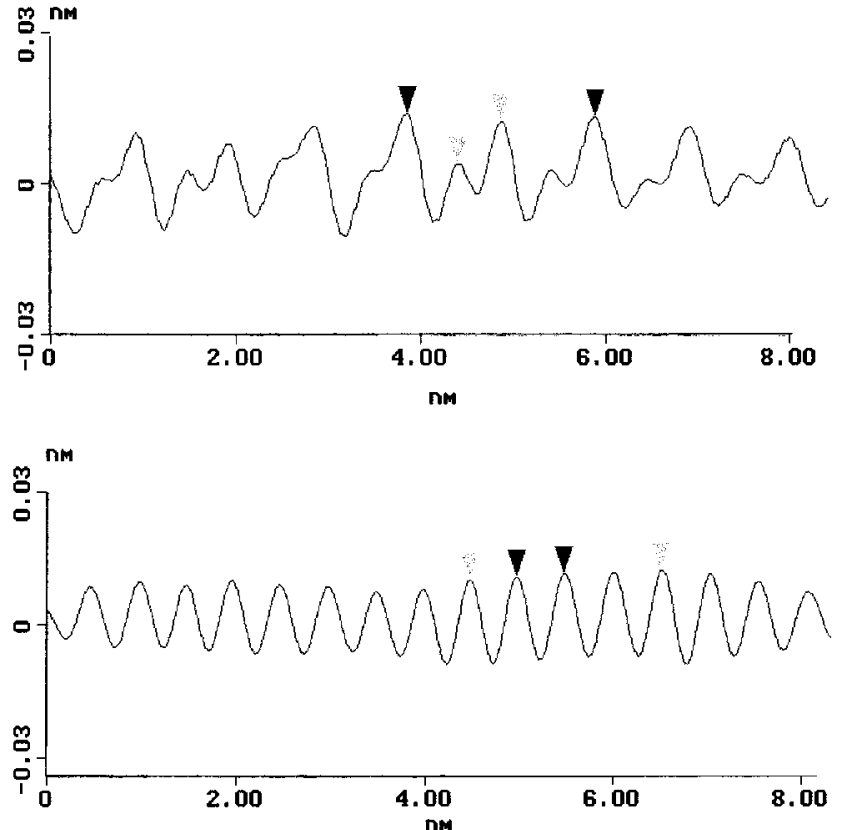

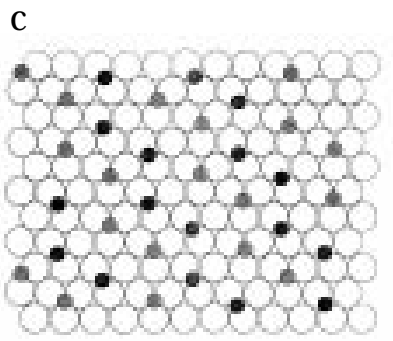

$\mathrm{nm}$

Figure 7. Ex situ high-resolution STM images and cross sections from 1-butanethiol-covered Au(111) at $298 \mathrm{~K}$, for $t=24 \mathrm{~h}$, in which the $\mathrm{c}(4 \times 2)$ lattice $(\mathrm{a})$ and the $(\sqrt{ } 3 \times \sqrt{ } 3) \mathrm{R} 30^{\circ}$ lattice (b) can be observed. (c) Scheme of the proposed model for the $\mathrm{c}(4 \times 2)$ lattice on $\mathrm{Au}(111)$. Open white circles denote the $\mathrm{Au}(111)$ lattice; small gray circles correspond to alkanethiol molecules at hollow sites; small black circles indicate alkanethiol molecules at bridge sites.

alkanethiol molecules from fcc to hcp hollow sites. This process is energetically favorable. ${ }^{40}$

On the other hand, the $(\sqrt{ } 3 \times \sqrt{ } 3) \mathrm{R} 30^{\circ} \Longrightarrow \mathrm{c}(4 \times 2)$ change has been observed for 1-decanethiol SAMs on Au(111) ${ }^{38}$ after either annealing or repetitive STM tip scanning of $(\sqrt{ } 3 \times \sqrt{ } 3) \mathrm{R} 30^{\circ}$ domains. In contrast to these results, our data for 1-butanethiol and 1-dodecanethiol SAMs on $\mathrm{Au}(111)$ indicate that the dynamics of these interfaces is more complicated than earlier thought, as there is evidence that the spontaneous $(\sqrt{ } 3 \times \sqrt{ } 3) \mathrm{R} 30^{\circ} \Leftrightarrow \mathrm{c}(4 \times 2)$ structural fluctuations take place.

The reversible structural fluctuation $(\sqrt{ } 3 \times \sqrt{ } 3)$ R30 $0^{\circ} \Leftrightarrow$ $\mathrm{c}(4 \times 2)$ can be explained as a consorting effect merging from different contributions in which various adsorbatesubstrate interactions are involved. Thus, considering that STM senses the methyl groups of the thiol molecules, one possibility that has already been proposed ${ }^{21}$ for this structural fluctuation is to associate it with changes in the tilt angle of the alkyl chains, a process that requires a low-energy change. Conversely, considering that STM senses mainly the position of the $S$ heads of alkanethiol molecules, ${ }^{29,39}$ then the reversible fluctuations can be related to the motion of alkanethiol adsorbates from hollow to bridge sites and vice versa. In this case, alkanethiol molecules at hollow and bridge sites result in a STM image contrast similar to that resulting from differences in the tilt angle of alkyl chains. Therefore, on the basis of exclusively STM imaging data, it is not possible to discriminate between these two explanations. However, in our opinion, the new model shown in Figure $7 \mathrm{c}$ is consistent with recently reported sum-frequency generation data of alkanethiol SAMs showing the presence of adsorbed molecules at bridge and hollow sites on the $\mathrm{Au}(111)$ surface $^{18}$ and with the theoretical estimation of the low-adsorption-energy difference between molecules located at hollow and bridge sites. ${ }^{40}$

For our experimental conditions, in contrast to the $(\sqrt{ } 3 \times \sqrt{ } 3) \mathrm{R}^{\circ} 0^{\circ} \Rightarrow \mathrm{c}(4 \times 2)$ alkanethiol SAM structural

(40) Beardmore, K. M.; Kress, J. D.; Bishop, A. R.; Gronbech-Jensen, N. Synth. Met. 1997, 84, 317. change $^{38}$, the $(\sqrt{ } 3 \times \sqrt{ } 3) \mathrm{R} 30^{\circ} \Leftrightarrow \mathrm{c}(4 \times 2)$ structural fluctuations occur irrespective of STM tip scanning and the alkyl chain length. Therefore, this means that other mechanisms providing the energy for the collective displacement of adsorbed thiol molecules have to be explored.

The fact that fluctuations in pit size do occur simultaneously with the adlayer lattice fluctuations turns out to be an important issue in dealing with the dynamics of thiol domains. Mechanisms for pit formation (see section 1) ${ }^{24-26}$ prior to SAM formation cannot account for the appearance of new pits in relation to the adlayer dynamics. Conversely, clustering theories (see section 3.1) account for both the decrease in the number of pits and the increase in pit size at $\mathrm{Au}(111)$, particularly at the early stages of SAM formation, where no ordered adsorbate adlayer can be distinguished. Otherwise, when ordered adsorbate domains are formed, fluctuations in pit size rather than pit clustering occur simultaneously with the adlayer structural fluctuations (Figure $5 \mathrm{a}$ and $\mathrm{b}$ ). This suggests that pit size fluctuations are coupled with adlayer structural fluctuations, leading to a kind of oscillating system. From these facts and the analysis of sequential STM images, a new explanation for the spontaneous adlayer lattice fluctuations including a possible energytransfer mechanism can be advanced.

The adsorption energy change $(\Delta E)$ related to the displacement of the alkanethiol molecule from a fcc to a bridge site on $\mathrm{Au}(111)$ is $\Delta E \approx 4.2 \mathrm{~kJ} / \mathrm{mol}$, whereas the adsorption energy change for transfer either from a hcp to a bridge site or from a hcp to a fcc site is $\Delta E \approx 4.2-8.4$ $\mathrm{kJ} / \mathrm{mol}{ }^{40}$ These values of $\Delta E$ are $2-4$ times greater than the thermal fluctuation energy of adsorbates at $298 \mathrm{~K}$. Accordingly, other possible energy contributions for promoting the adlayer structural fluctuations have to be discussed.

Typical changes in the size of randomly distributed pits accompanying alkanethiol adlayer lattice changes are of about $100 \mathrm{~nm}^{2}$ in surface area. Then, taking for the surface tension of $\mathrm{Au}(111)$ at $298 \mathrm{~K} \gamma \cong 1000 \mathrm{erg} / \mathrm{cm}^{2}$, a decrease of $1 \mathrm{~nm}^{2}$ in surface area would mean an energy release 


\section{a (0 s)}

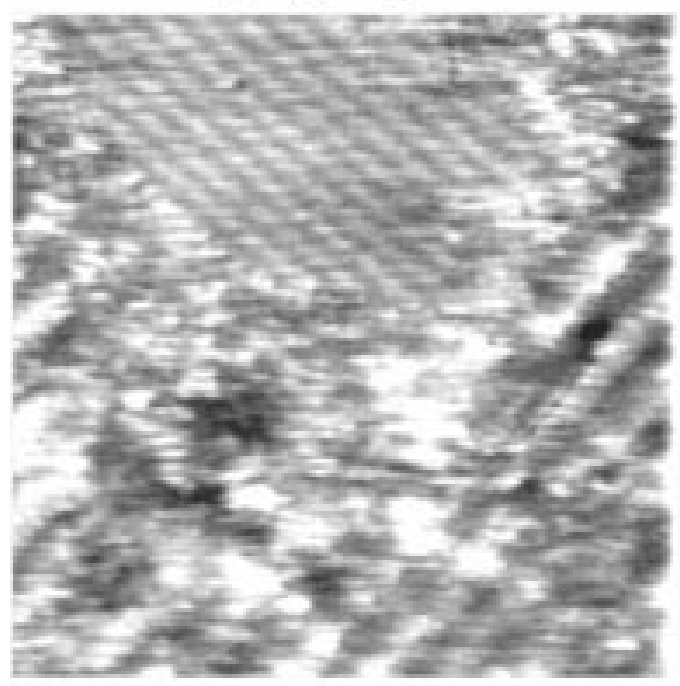

\section{c (461 s)}

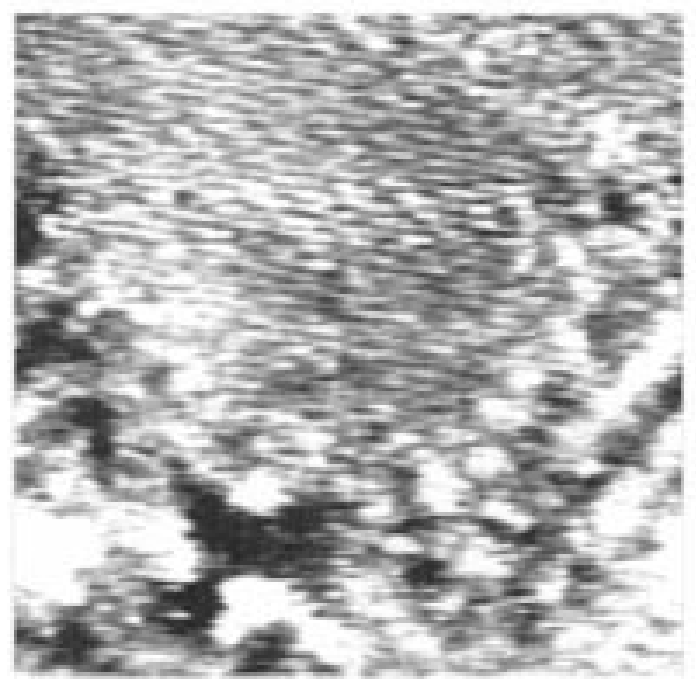

b $(420 s)$

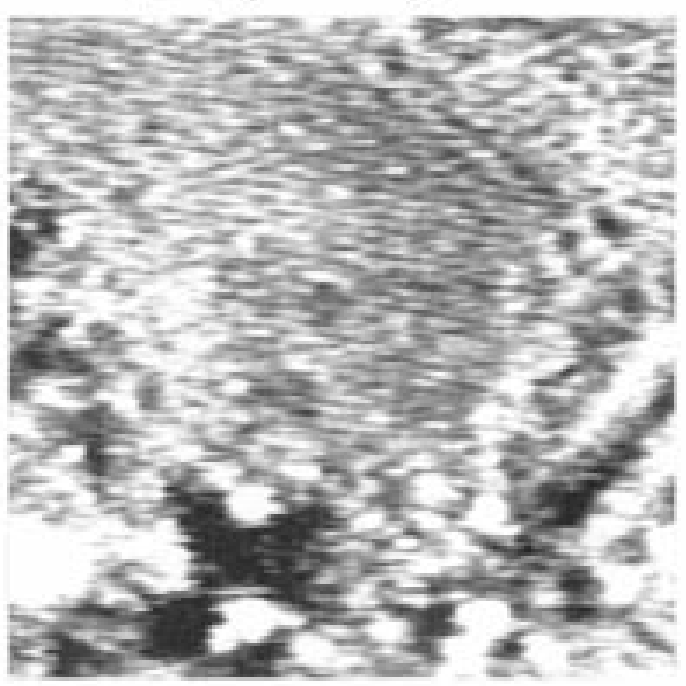

d (478 s)

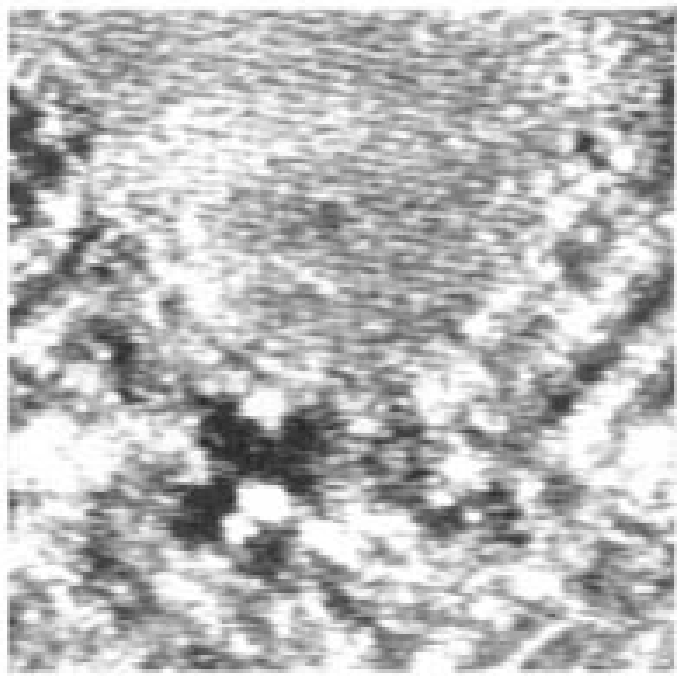

Figure 8. Sequential ex situ STM images from 1-butanethiol-covered Au(111) at $298 \mathrm{~K}$ for $t=24 \mathrm{~h}$. The reversible lattice change $\mathrm{c}(4 \times 2) \Leftrightarrow(\sqrt{ } 3 \times \sqrt{ } 3) \mathrm{R} 30^{\circ}$ can be followed for different emersion times, as indicated in the figures.

of about $10^{-11} \mathrm{erg}$. This energy can be either dissipated in the surroundings or used by adsorbed molecules to change the position from hollow to bridge sites, promoting the $(\sqrt{3} \times \sqrt{3}) \mathrm{R} 30^{\circ} \Longrightarrow \mathrm{c}(4 \times 2)$ change. Hence, the amount of energy released in the pit area decrease becomes sufficient to assist the change in the position of nearly 200 adsorbed molecules occupying a $13 \times 13 \mathrm{~nm}^{2}$ domain. Otherwise, when thiol molecules are involved in the reverse process, that is, the $c(4 \times 2) \Longrightarrow(\sqrt{ } 3 \times \sqrt{ } 3) \mathrm{R} 30^{\circ}$ change, moving adsorbate molecules from bridge to hollow sites, energy is required to grow small pits. Then, the repetitive process would lead to a fluctuating quasi 2D system with a small damping.

In conclusion, our results indicate that 1-butanethiol and 1-dodecanethiol adsorbates on $\mathrm{Au}(111)$ undergo $(\sqrt{ } 3 \times \sqrt{ } 3) \mathrm{R} 30^{\circ} \Leftrightarrow \mathrm{c}(4 \times 2)$ structural fluctuations. This fact, which should be considered in the description of the thiol adlayer dynamics, would be particularly important to elucidate the mechanism of phase changes at adsorbate layers. Unfortunately, from our results it is not possible to determine the preferential direction of these fluctuations leading to the most stable adlayer configuration. For the latter purpose a statistical analysis of a large number of molecular resolution STM images to be averaged out over the entire surface should be used, as already proposed for imaging of macroscopic defects. ${ }^{41}$ However, this procedure is usually very difficult, particularly when a large collection of images at the molecular level has to be obtained. In this case, from average surface analysis data the more stable adsorbate configuration can be concluded.

Finally, it is worth noting that our results and conclusions from alkanethiol adsorption on $\mathrm{Au}(111)$ reported in this work have to be cautiously compared to those resulting from similar SAM adlayers prepared under different conditions. The structural fluctuations observed in our work appear to be coupled to the relaxation of surface defects that provides the energy for the overall process. Therefore, structural fluctuations at defect-free surfaces would be difficult to be detected. This fact could explain the different results ${ }^{38}$ reported in the literature on the structural dynamics of SAMs on Au(111).

(41) Williams, D. E. Surf. Sci. 1994, 299/300, 502. 


\section{Concluding Remarks}

In conclusion, for our experimental systems, processes taking place during alkanethiol SAM formation on $\mathrm{Au}(111)$ at $298 \mathrm{~K}$ involve changes in the entire surface consisting of adlayer domains and pits. At the adlayer level, changes can be represented as follows

$$
\text { disordered (gas-like) } \Rightarrow \mathrm{p}(\mathrm{n} \times 1) \Rightarrow(\sqrt{ } 3 \times \sqrt{ } 3) \mathrm{R} 30^{\circ} \Leftrightarrow \mathrm{c}(4 \times 2)
$$

and at the substrate level, the can be represented as

initially formed pits $\Rightarrow$ coalescence at terrace borders

$\Downarrow$

coalescence at terraces $\Leftrightarrow$ small pit formation.
These processes determine the global dynamics of the system, and the coupling of the two reversible processes can explain the onset of a fluctuating system with a low damping constant.

Results and conclusions from this paper indicate that further structural work for these systems at the molecular level should be encouraged to attain a more complete description of the complex and rich dynamics of alkanethiol adlayers on $\mathrm{Au}(111)$ at $298 \mathrm{~K}$.

Acknowledgment. Financial supports from the Consejo Nacional de Investigaciones Científicas y Técnicas, CONICET (PIP 014/97, PIA 7283/97), Comisión de Investigaciones Científicas de la Pcia. de Buenos Aires, are acknowledged. F.T.A. thanks the fellowship granted by CONICET.

LA9805286 